\title{
Exploring antecedents of experimentation and implementation of the balanced scorecard
}

\section{Geert BraAm}

Radboud University Nijmegen, Nijmegen, The Netherlands

\section{Ed NiJSSEN}

Eindhoven University of Technology, Eindhoven, The Netherlands

\section{ABSTRACT}

Adoption of management innovations like the balanced scorecard is generally a complex process. Many subdecisions are involved and customization is often required before firms can enjoy the benefits of these innovations. Consequently, firms tend to experiment before finally implementing such complex innovations. We develop a framework differentiating between antecedents of experimentation with and actual implementation of the balanced scorecard, a distinction that has largely been neglected in the literature. Focusing on a small set of firms that experimented with the balanced scorecard, we provide initial empirical evidence. The results support the framework showing that top management involvement, innovation-contingent departments and organizational-context factors play a significant positive role in the experimentation stage, while interdepartmental communication and formalization are important variables with positive and negative influences in the implementation stage. We discuss the findings and their managerial implications.

Keywords: adoption, experimentation, balanced scorecard, management innovations

\section{INTRODUCTION}

$\mathrm{T}$ he balanced scorecard (BSC) is an important recent management innovation. It bridges the accounting and strategic management literatures and uses a comprehensive view of business processes that managers need to monitor and manage carefully to achieve corporate success in the marketplace. Managers' expectations are high. It explains why there is considerable managerial and academic interest in this relatively new management tool. However, like other management innovations the BSC lacks detailed 'product specifications', which make its interpretation and implementation difficult at best (Ahn, 2001).

Overtime the developers of the BSC extended and refined the instrument. First introduced by Kaplan and Norton (1992) as a strategic performance measurement system, the BSC is designed to provide managers with a way of translating firm strategy into a set of financial and non-financial measures covering four different domains of the organization. Although Kaplan and Norton (1992) emphasized that 
'The Balanced scorecard puts strategy - not control - at the center', directions on how to link an organization's strategy formulation and its measurement system were limited. From 1996 on the authors have extended their view, developing and formally proposing it as a strategic management system. They have described and explained the tool's management processes and principles in more detail and have shown how strategy may be 'mapped' using a formal and integrated set of financial and non-financial strategic performance measures allowing for alignment between the control system and firm strategy (Kaplan, 2010; Kaplan \& Norton, 1996, 2001, 2004, 2006).

Despite these refinements empirical research confirms that different interpretations of the BSC exist. Results also show that managers find the BSC hard to use and think that its positive influence on business is uncertain (De Geuser, Mooraj, \& Oyon, 2009; Ittner, Larcker, \& Randall, 2003; Speckbacher, Bischof, \& Pfeiffer, 2003). Opening up the black box of BSC adoption could help reduce the uncertainty about its expected consequences for an organization's competitive position and performance and help managers in introducing the instrument more successfully.

Case-based research has provided us with a better understanding of the BSC in practice. Ahn's (2001) work, for instance, illustrates how firms can use experimentation as an important first step to advance their knowledge about the benefits and costs of the BSC before its fully fledged adoption. The initial experiences gained through pilot projects, e.g., workshops, helped the firm to identify problems and develop a customized version of this performance measurement-based management innovation to suit the needs of the organization and its employees. Next, top management moved ahead with the implementation. Ahn's (2001) research shows that an initiation and implementation stage can be distinguished and also suggests that different antecedents influence these subsequent stages.
However, although innovation adoption has been conceptualized as a process, the different antecedents of these stages have hardly been explored in the literature (Damanpour \& Schneider, 2006; Krumwiede, 1998; Wolfe, 1994). Few studies have addressed the issue, which seems particularly relevant for better understanding the way organizations adopt complex management innovations like the BSC. Because the BSC needs to be detailed carefully and customized to the prevalent organizational conditions, a more detailed understanding of the facilitating or inhibiting factors in this adoption processes will be extremely useful.

The objective of this study is to explore the different antecedents of (i) experimentation and (ii) implementation in the adoption process of the BSC. Whereas adoption research has typically considered the same antecedents for these two stages, we propose that different factors drive experimentation and implementation (see also Olshavsky \& Spreng, 1996). We provide initial empirical evidence for our claim using a small sample of firms that have adopted the BSC.

Our study contributes to the literature in several ways. First, it contributes to the domain of accounting and control. Few studies have researched the antecedents of BSC adoption and much of this research is anecdotal or case-based (Malmi, 2001; Modell, 2009). Quantitative results are growing but scant and additional results might help to better understand the relative importance of the different factors involved in the experimentation and implementation stages of BSC adoption (Hoque \& James, 2000; Ittner et al., 2003). Second, we introduce BSC specific antecedents, i.e., the influence of the finance department and the role of firm's intangibles assets in the adoption decision. Third, this research adds to the literature on management innovations. The adoption of management innovations is a complex process that consists of various stages (Rogers, 2003). Little attempts have been made to deconstruct this 
process, showing the differential influence of antecedents per stage of adoption (Krumwiede, 1998; Malmi, 2001). This study adds by distinguishing between experimentation and implementation.

The remainder of the article is organized as follows. The next section develops a theoretical model of the adoption process for administrative innovations, recognizing that most organizations experiment with these innovations before they move ahead and implement them. Consistent with this observation we develop hypotheses related to antecedents influencing the experimentation and implementation stages of the adoption process of the BSC. The research method section is discussed next, followed by a discussion of the empirical results. Finally, we draw conclusions and discuss managerial implications and limitations of our study.

\section{DEVELOPMENT OF A THEORETICAL MODEL \\ A two stage model of adoption}

Adoption refers to 'the process through which an individual (or other decision-making unit) passes from gaining initial knowledge of an innovation, to forming an attitude toward the innovation, to making a decision to adopt or reject, to implementation of the new idea, and to confirmation of this decision' (Rogers, 2003, p. 168). Organization decision-makers have to pass through these different stages of the process, because of the perceived newness of a management innovation, like the BSC, and the uncertainty and risks associated with its newness. It helps them to obtain a better understanding of the innovation and to link it to their organization's needs and mental model (Meyers-Levy \& Tybout, 1989). In this paper we borrow from the extant literature a model with two stages of adoption: (i) experimentation and (ii) implementation (Damanpour \& Schneider,
2006; Rogers, 2003; Zaltman, Duncan, \& Holbek, 1973). ${ }^{1}$

Experimentation refers to what Rogers (2003) calls the knowledge and persuasion stage. The organization recognizes the need for change, becomes aware of the innovation, and decides if it wants to learn more about the innovation. This stage involves a careful review of the innovation's advantages and disadvantages for the organization, to reduce uncertainty about the innovation's expected consequences for managing business processes and firm performance. As part of the information-seeking and informationprocessing activity, experimentation contributes to organizational learning by improving managers' understanding of facilitating or inhibiting factors in the adoption of the complex innovation (Rogers, 2003; Wouters \& Wilderom, 2008). More specifically, experimentation concerns the early advancement of a firm's knowledge about the expected benefits of an innovation and the exploration of its particularities and consequences under field conditions before actual adoption and implementation (e.g., Ahn, 2001). It serves the reduction of possible ambiguity and helps adjusting the innovation to a firm's particular situation (Santa, Ferrer, Bretherton, \& Hyland, 2009). It involves according to Wouters and Wilderom (2008, p. 507) a 'process of tinkering ... while designing and implementing it'. Exposure to and positive outcomes of experimentation are critical in moving forward with the adoption decision but also help to build an organization's commitment (Rogers, 2003).

Drivers of initiation and experimentation are top management and managers of departments that have a particular interest in an innovation. Top managers enact the environment and develop a firm's strategy (Hambrick \& Mason, 1984). As tool to shape strategy (re)formulation processes the BSC is typically relevant for top managers

\footnotetext{
Aware of the debate about the number of stages of the adoption process, we would like to point out that our objective is not to contribute to this discussion but rather to take a first step in deconstructing the decision and illustrating the differential effect that adoption characteristics have for each stage.
} 
(Kaplan, 2010; Kaplan \& Norton, 2001, 2004). Furthermore, because the BSC is in essence a performance measurement-based control instrument also accounting people will be involved. The tool can help increase their importance in the firm, but also help address several developments in the firm's business environment such as environmental turbulence (Pfeffer \& Salanick, 1978). In addition, the BSC can help firms to strategically align their intangibles. Consequently, firms relying heavily on intangible assets as a source of competitive advantage are more likely to experiment with the BSC (Kaplan, 2010; Kaplan \& Norton, 2001, 2004).

The next stage is actual implementation, which involves the actual roll-out of the innovation in its final and full form 'organization-wide' (Meyer \& Goes, 1988; Rogers, 2003). In this stage the acceptance or assimilation by the organization of the innovation, i.e., the BSC, becomes important. The new ideas and behaviours have to become accepted and integrated by departments and individual members of the organization (Frambach \& Schillewaert, 2002). Rogers (2003) refers to this as confirmation and persuasion. This stage of adoption builds general commitment, allocates resources to the innovation, and leads to sustained implementation and use of the innovation (Rogers, 2003; Zaltman et al., 1973).

Implementation characterizes the shift from a new, first time use to more routinized usage behaviour. It involves the actual decision to continue using the innovation based on experimental results, and is characterized by (i) a stable group of people working 'infinite' with the BSC, (ii) minor rather than substantial changes to the instrument, and (iii) regular cycles to fill in and evaluate the scorecards (Kaplan, 2010). Drivers of this stage will again be top management and the finance department; they will support the decision to continue and accompany the implementation, respectively. Furthermore, because of the organization-wide impact of the BSC, there is also a need for departments to understand the tool and cooperate with its use. Hence, excellent interdepartmental communications and overcoming potential countervailing powers, emerging from high levels of formalization, will be important.

\section{DEVELOPING A FRAMEWORK AND HYPOTHESES \\ Framework}

Figure 1 shows our framework of BSC adoption that distinguishes between the stages of (i) experimentation and (ii) implementation. These adoption stages are shown on the right hand side of the Figure 1. Antecedents of experimentation and implementation are shown on the left hand side. Consistent with Rogers (2003), three types of antecedents that influence a firm's likelihood to adopt an innovation are present: leadership characteristics of the organization's management (top management involvement), internal organizational characteristics (interdepartmental communications, and formalization), and environmental or external company characteristics (environmental dynamics). However, two BSC specific factors are also included: influence of finance department and intangible assets. Although other factors might be anticipated these are considered to be the most important ones, which also might be argued to have - to some extent - a different effect on our two stages of adoption, as was mentioned in the previous section.

\section{Hypotheses}

Consistent with Wouters and Wilderom's (2008) qualitative results, experimentation is argued to precede the implementation stage, which characterizes an organization's formal decision to continue using and also roll-out the innovation organization-wide. As these authors note, 'New performance measures are hardly ever "right" straight away'. Employees typically use key and often tacit knowledge to test and refine performance measures. This occurs in multiple cycles and helps to not only build commitment but also to arrive at a set of performance measures that is more reliable, valid, and understandable in the specific context of a firm. Based on these 


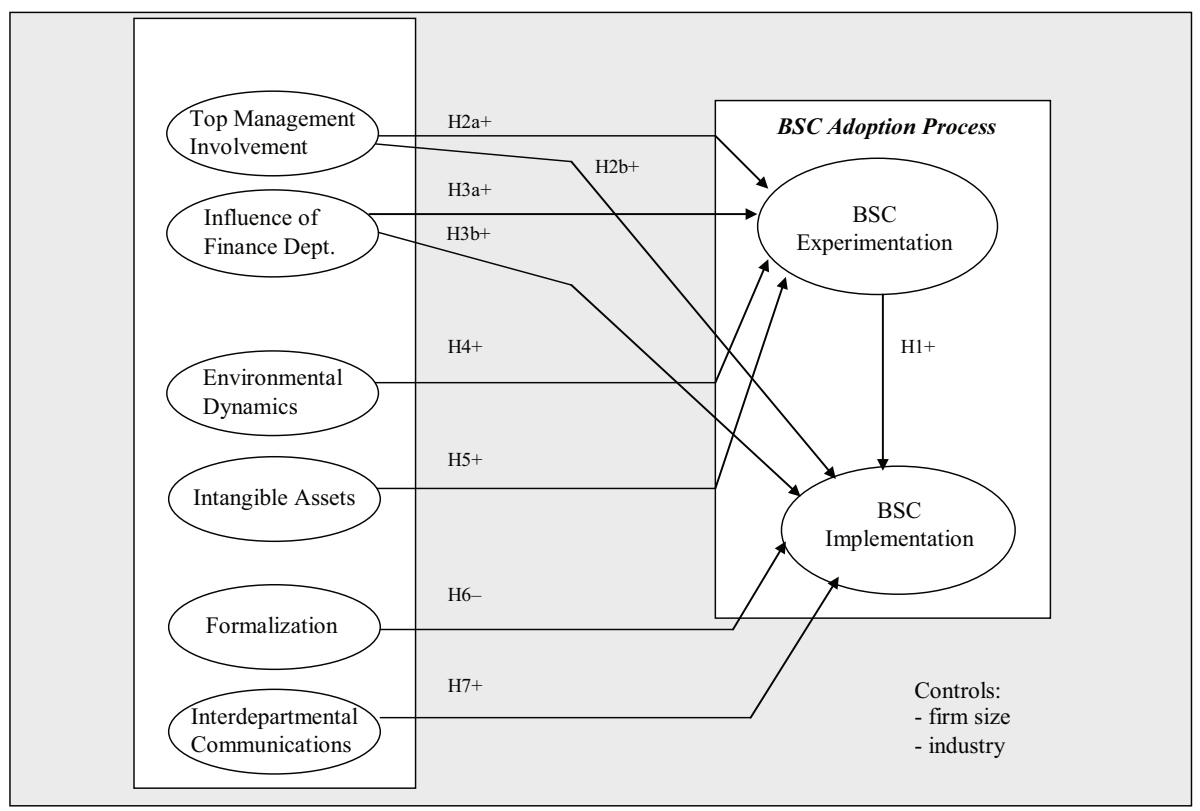

Figure 1: ANTECEDENTS of BSC experimentation AND IMPLEMENTATION

qualitative results, and expecting the experimentation efforts to pay off, a positive relationship is anticipated.

H1: BSC experimentation is positively related to BSC implementation

Top management and the organizational influence of the finance department are anticipated to affect both an organization's decision to begin experimentation with the BSC and its implementation. These variables relate to the relevant parties in the decision-making unit that may initiate BSC adoption. Top managers play an important role in many innovation adoption decisions (Rogers, 2003). Their interest in and commitment to exploring complex management innovations are crucial for the initial decision to move ahead, specifically also for an important strategy formulation and implementation tool such as the BSC (Ahn, 2001; Assiri, Zairi, \& Eid, 2006). Top management involvement helps to create commitment and generate support for the BSC in organizational departments and with individuals (Kaplan \& Norton, 2001).
The finance department will also be involved. Management accountants will have specific, professional knowledge gained partly from common education and training, on how the organization might benefit from adopting and using this strategic performance measurement tool. As a consequence, the finance department may be a very important advocate for trying out and implementing the BSC and helping reduce uncertainty emerging from the environment pressuring the firm to adopt the BSC (Pfeffer \& Salancik, 1977). So, the more influential this department the more likely the BSC will be considered and adopted. Hence,

H2a: Top management involvement is positively related to experimentation with BSC.

$\mathrm{H} 2 \mathrm{~b}$ : Top management involvement is positively related to BSC implementation.

$\mathrm{H} 3 \mathrm{a}$ : Influence of the finance department is positively related to experimentation with BSC.

$\mathrm{H} 3 \mathrm{~b}$ : Influence of the finance department is positively related to BSC implementation. 
We also include two organizational-context characteristics, which we expect - due to their general nature - to only influence an organization's experimentation with the BSC. First, we account for the level of dynamics of the firm's markets (Rogers, 2003). Firms operating in turbulent environments need more flexibility to respond effectively to technological and other trends (Lee, Chu, \& Tseng, 2009; Miles \& Snow, 1978). The BSC extends conventional measurement systems to also include innovation and growth and thus may appeal particularly to firms operating in volatile environments (Baines \& Langfield-Smith, 2003). These firms may be more inclined to consider adoption, and thus experiment with ways to measure this side of their business and business processes.

Second, we account for the level of the firm's intangibles. Unlike physical and financial assets, intangibles, like human, information and customer capital, are hard for competitors to imitate, which makes them a powerful source of sustainable competitive advantage (Kaplan, 2010; Kaplan \& Norton, 2001, 2004). The BSC helps firms to monitor and strategically align their intangible assets to corporate strategy (Kaplan, 2010). Recently it has been argued that firms whose competitive position is more dependent on effective exploitation of its intangible assets require more careful strategic control and monitoring mechanisms and thus are more likely to consider the BSC (Ittner, 2008). Consequently, firms with high levels of intangible assets are expected to be more likely to experiment with the BSC to advance their knowledge about its value for the organization and its particularities and consequences under field conditions. The firm's level of intangibles is a BSC-specific adoption characteristic. Based on the above we propose,

H4: Environmental dynamics is positively related to experimentation with BSC.

$\mathrm{H} 5$ : Intangible assets are positively related to experimentation with BSC.
Two internal organizational characteristics are anticipated to affect the implementation of the BSC by an organization: formalization, and interdepartmental communication. Formalization represents the degree to which jobs within an organization are standardized and have a formal status making individual departments formally responsible for a particular business domain. The literature shows that companies with a highly structured, formal organization are less likely to come into contact with innovations than their less formalized counterparts and may experience more resistance (Jaworski \& Kohli, 1993). While the former may not apply to a broad management tool such as the BSC, the latter is all the more relevant. Formal procedures and highly standardized processes act as barriers, thus negatively influencing BSC's implementation. Being 'forced' to implement the BSC may be felt as a breach of formal authority and the specialized terrain of a department and its staff. Allowing employees to adjust the BSC as they see fit can help motivate them, but formalized processes and delineations of tasks may still make implementation difficult.

Interdepartmental communication is known to facilitate implementation (Rogers, 2003). It helps to generate a common understanding, support, and commitment for implementation of complex management innovations like the BSC. Specifically, interdepartmental communication may help to reduce ambiguity, and integrate and align the multidimensional performance indicators of different departments into a single 'strategy map' (Kaplan, 2010; Kaplan \& Norton, 2001, 2004). A high level of information exchange between organizational departments allows for resolving differences and overcoming resistance. In conclusion we propose the following hypotheses,

H6: Formalization is negatively related to BSC implementation.

H7: Interdepartmental communication is positively related to BSC implementation.

Volume 17, Issue 6, November 2011 


\section{RESEARCH METHOD Data collection and sample}

The framework was tested using a sample of Dutch firms drawn from a database of firms that attended a seminar on best practices in management control conducted by an international consulting firm. Using telephone prescreening, we then identified those firms using a BSC or a BSC-like strategic performance measurement system (Assiri et al., 2006; Malmi, 2001; Speckbacher et al., 2003). In total 80 firms agreed to participate. After pretesting the questionnaire, it was mailed to them, together with a personalized cover letter and using a summary of research findings as an incentive. A reminder letter was sent and a follow-up phone call made two weeks later to increase the response rate.

After four weeks 45 responses had been received, representing a response rate of $56 \%$. Five cases were omitted from the final analysis because of incomplete data in the study constructs. The respondents were mainly management accountants and financial directors/managers (94\%). Despite a bias towards capital goods companies, the sample profile was consistent with the distribution of our sampling frame. A brief sample profile is presented in Table 1.

\section{Measurement of variables}

All independent constructs except organization's intangible assets were measured using multiple items drawn from existing measures and using five-point Likert-type scales ( $1=$ 'strongly disagree'; $5=$ ='strongly agree'). Appendix A provides an overview. Top management involvement was measured using three items referring to management's interest in and commitment to comprehensive performance management (Zaltman et al., 1973). The operationalization of the influence of the finance department was adapted from Pfeffer (1981) and used two items. The level of firms' environmental dynamics was operationalized using three items based on Miller and Friesen (1982) and Naman and Slevin (1993). Formalization and interdepartmental communication were measured using four and three items, respectively, and were adapted from Covin and Slevin (1991) and Jaworski and Kohli (1993). Finally, the data regarding organizations' intangible assets were based on secondary data and collected from the consolidated balance sheets in the firms' annual reports. To develop a relative measure, the value of an organization's intangible assets was divided by firm size measured by the number of employees.

TABle 1: Profile of the ReSPONDENTS (ALL NUMBERS ARE IN PERCENTAGES)

\begin{tabular}{|c|c|c|c|c|c|c|c|}
\hline $\begin{array}{l}\text { Company } \\
\text { size }\end{array}$ & (\%) & Industry & (\%) & $\begin{array}{l}\text { Respondent's function } \\
\text { within the company }\end{array}$ & (\%) & $\begin{array}{l}\text { Respondent's } \\
\text { years with } \\
\text { company }\end{array}$ & (\%) \\
\hline$<50$ & 2.4 & Food & 12.2 & $\begin{array}{l}\text { Director business } \\
\text { development }\end{array}$ & 5.9 & $<2$ & 11.8 \\
\hline $50-500$ & 63.4 & Natural products & 14.6 & Financial director & 11.8 & $2-5$ & 35.2 \\
\hline $501-1000$ & 22.0 & Oil, gas, chemicals & 29.3 & $\begin{array}{l}\text { Financial manager/head } \\
\text { of finance \& accounting } \\
\text { department }\end{array}$ & 35.3 & $6-10$ & 11.8 \\
\hline \multirow[t]{2}{*}{$>1000$} & 12.2 & Capital goods & 43.9 & Management accountant & 29.4 & $>10$ & 41.2 \\
\hline & & & & $\begin{array}{l}\text { Assistant management } \\
\text { accountant }\end{array}$ & 17.6 & & \\
\hline Total & 100.0 & & 100.0 & & 100.0 & & 100.0 \\
\hline
\end{tabular}


Our first dependent construct, BSC experimentation, refers to the organization's degree of experimentation with the BSC before actual implementation. It was measured using two items, one directly referring to experimentation behaviour and a second that addressed the level of adjustment of the BSC and its four perspectives, e.g., having developed alternative performance measures. Our second dependent construct, BSC implementation, was operationalized as a formative construct and draws on Malmi (2001) and Speckbacher et al. (2003). It used four items referring to the distribution of attention over the four perspectives of the BSC i.e., financial, customer, internal business processes, and learning and growth. In contrast to a reflective construct, a formative construct's measures are no substitutes, but together determine the latent variable (Diamantopoulos, Riefler, \& Roth, 2008, p. 1205).

\section{Statistical analysis}

The data was analysed in two consecutive stages. First, the data was explored and the measurement validity and reliability were evaluated. Appendix B shows the means and standard deviations, as well as the reliability and the average variance extracted (AVE) for each construct. Composite reliabilities exceeded 0.7 (except for interdepartmental communications 0.63) indicating acceptable internal levels of consistency. Further, AVE ranged from 0.53 for interdepartmental communications and formalization to 0.91 for the influence of the finance department. Comparing the square roots of the AVE with the correlations between the different constructs, we found that all exceeded the construct's intercorrelation with any of the other study constructs (see Appendix B for the correlation matrix), providing support for their discriminant validity (Fornell \& Larcker, 1981).

Second, we used SmartPLS (2.0) to obtain partial least squares (PLS) estimates for both our structural and measurement parameters in our structural equation model (Chin, 1998; Ringle, Wende, \& Will, 2005). PLS is recommended for relatively small sample sizes (Barclay, Higgins, \& Thompson, 1995), has the advantage of allowing for inclusion of formative constructs, and has no restrictions concerning the distribution of variables. To test the statistical significance of the hypothesized relationships in the structural model, we used the SmartPLS bootstrapping procedure with 500 samples to derive stable results (Chin, 1998). The data were first standardized before entering them in the analyses. Firm size and industry dummies ${ }^{2}$ were included as control variables to ensure correct model estimation; larger firms are more likely to adopt complex management innovations (Rogers, 2003).

\section{RESULTS}

The results of the structural model estimated using PLS are shown in Table 2. The results suggest that the model explains non-trivial variance in the dependent constructs of experimentation $\left(R^{2}=0.83\right)$, and implementation $\left(R^{2}=0.73\right)$. Furthermore, BSC experimentation had a positive and significant relationship with BSC implementation as anticipated $(b=0.38, p<0.01)$. This provides support for $\mathrm{H} 1$.

Turning to the results of the antecedents, we note that Top Management Involvement and Influence of the Finance Department had a significant positive impact on BSC Experimentation. The effects were strong $(b=0.32, p<0.05$, $b=0.36, p<0.01$ respectively), suggesting that these actors are very important indeed when a firm is considering and testing the BSC. It provides support for $\mathrm{H} 2 \mathrm{a}$ and $\mathrm{H} 3 \mathrm{a}$, respectively. For the two organizational-context variables, environmental dynamics and intangible assets, we found a positive significant effect $(b=0.26$, $p<0.10)$ and a positive but non-significant

\footnotetext{
2 In the final analyses only the (significant) industry dummy for 'natural products' was retained.
} 
TABLE 2: PLS RESULtS REgARDING the EFFECTS OF THE ANTECEDENTS ON BSC EXPERIMENTATION AND IMPLEMENTATION

Dependent variables:

Independent variables
BSC adoption process

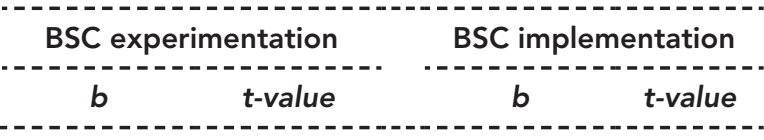

$\begin{array}{llll}0.32 & 2.8^{\star} & 0.17 & 1.7^{\dagger} \\ 0.36 & 2.8^{\star \star} & 0.03 & 0.3 \\ 0.26 & 1.9^{\dagger} & & \\ 0.18 & 1.4 & & \end{array}$

Intangible assets (H5)

0.38

$2.9^{* *}$

BSC experimentation ( $\mathrm{H} 1)$

$-0.30$

$2.1^{*}$

Formalization ( $\mathrm{H} 6)$

0.24

$2.3^{*}$

Interdepartmental communications $(\mathrm{H} 7)$

Controls

Firm size

$-0.10$

0.9

$-0.07$

0.7

Industry (natural products)

$-0.19$

1.4

$-0.42$

$3.6^{* *}$

Variance explained

$R^{2}=0.83$

$R^{2}=0.73$

$*, * *,+$, Significant at $0.01,0.05$ and 0.1 levels respectively (two-tailed).

effect $(b=0.18, p>0.10)$ respectively. The former result is as expected. The latter result does not support Kaplan and Norton's suggestion that the BSC would help to measure and manage an organization's intangible assets better and thus that firms with important intangible assets more readily gravitate towards BSC adoption. We will return to this later. Together these results show confirmation of $\mathrm{H} 4$ and lack of support for $\mathrm{H} 5$.

Focusing on the effects of the antecedents of BSC implementation, the results confirmed a direct positive impact of top management involvement on BSC implementation, as anticipated $(b=0.17, p<0.10)$. Although the effect is only borderline, it lends support to $\mathrm{H} 2 \mathrm{~b}$. However, the results do not support $\mathrm{H} 3 \mathrm{~b}$ because the direct influence of the finance department on BSC implementation was positive but not significant $(b=0.03, p>0.10)$. We will explain this unexpected finding later. In addition, the results show that formalization negatively impacted implementation as expected $(b=-0.30, p<0.05)$. So, there is support for
H6. The effect of interdepartmental communication on BSC implementation was positive and significant $(b=0.24, p<0.05)$. Consistent with Kaplan and Norton's (2001, p. 217) observation, communication is 'a major lever for organizational success' regarding BSC adoption and probably also has a major contribution to developing a balanced set of scorecards. This finding provides support for $\mathrm{H} 7$.

\section{CONCLUSION AND DISCUSSION}

This study explores the antecedents of BSC adoption, recognizing $\mathrm{BSC}$ adoption as a complex process and differentiating between an experimentation and implementation stage in the adoption process. In an attempt to deconstruct this process, we hypothesized unique antecedents of experimentation and implementation, and tested our hypotheses using a sample of firms that had been involved in the adoption of the BSC. The results provided support for our framework of multistage adoption with different drivers per stage. The data explained a good deal of the variance in the data and supported most of our hypotheses. 
The results show that the initial decision to consider and try the BSC benefited from serious top management involvement. Top management plays a key role in initiation of and experimentation with a complex management innovation like the BSC. Compared with findings in previous adoption research (e.g., Rogers, 2003), we note that top management's role may be even more pronounced as the BSC involves a comprehensive management tool for strategy development and implementation. The fact that the influence of the finance department on experimentation with the BSC was also high is not surprising; the $\mathrm{BSC}$ is a performance measurement tool, which makes the finance department an obvious participant in the adoption decision. Furthermore, BSC use enhances the importance and power of the finance department (Pfeffer \& Salancik, 1977).

The positive effect of environmental dynamics on experimentation was also anticipated and found. It confirms that firms confronting a turbulent technological and market environment experiment more with the BSC than their counterparts from less turbulent industries. Under conditions of high turbulence managers need and prefer to rely on more and better performance measurement systems and thus invest more time and effort in experimentation. The organization's level of intangible assets had a positive but not significant (two-tailed) effect on experimentation with the BSC. Closer examination shows the effect is marginally significant using a less strict one-tailed test $(p<0.10)$. So, although results do not firmly support the anticipated effect they do point in the right direction, and support the suggestion that firms relying more on intangibles are more attracted to and experiment more with the BSC. Probably, these firms anticipate more relative advantages of using the BSC, motivating them to make further inquiries.

The decision to implement the BSC and actually put it to work was positively influenced by BSC experimentation, as well as affected directly by top management involvement, the organization's level of formalization, and interdepartmental communications. These results confirm that experimentation with the performance measurements of the BSC positively influences the decision to actually adopt and implement this strategic performance measurement tool. These findings suggest that testing under field conditions increases firms' confidence in an innovation and helps to make the next step in the adoption decision process, i.e., implementation. Specifically, it helps to advance management's knowledge about the effectiveness of the innovation in their specific organizational context while reducing uncertainties and risks associated with it.

Consistent with our expectations, the results suggest that top management involvement helps to create commitment and generate support for the tool in organizational departments and individuals. However, the fact that the influence of the finance department does not significantly affect BSC implementation is surprising. A possible explanation is that the BSC is a broad tool affecting many functional areas in the organization. As a result the influence of the finance department is moderated by other departments and organizational-context factors. More research will be needed to explore this conjectural explanation. Further, there was, of course, an indirect significant effect of finance department's influence on implementation via experimentation $(0.36 \times 0.38)$.

Our result also confirmed the anticipated negative influence of formalization on the implementation of the BSC. Based on their expertise individual departments may hinder BSC implementation, arguing, for instance, that performance in their area may be hard to capture in financially oriented indicators (see e.g., Jenkins \& Meer, 2005). At the same time extensive interdepartmental communication had a positive effect, and thus facilitated implementation. Internal communication helps overcome resistance and differences. This finding is consistent with previous results reported in the literature (Ahn, 2001; Assiri et al., 2006; De Geuser et al., 2009; Santa et al., 2009). 


\section{LIMITATIONS AND FUTURE RESEARCH}

Like all studies, this research suffers from a number of limitations, which suggest some directions for future research. In the first place, the study was a cross-sectional survey, conducted in a single country and institutional context, the Netherlands. Additional studies and longitudinal work would be needed to get a better handle on the causal relationships posed and to be able to research the effects of institutional field and national culture on BSC adoption.

Secondly, our sample was small, and covering a limited set of companies in a limited number of industries. Focusing on BSC adopters, we were able to study different stages of the adoption process without losing observations. However, this may limit the generalizability of findings to some extent. Further research is needed using large samples.

Thirdly, we only distinguished two stages of adoption and a limited set of antecedents. In the literature more stages of adoption have been identified that could be used in future research (Rogers, 2003). Using more stages could help to further deconstruct the adoption process of the BSC. Additional antecedents could be considered, such as industry or network effects and the role of the firm's management consultants and other peer influence. Further, research could also formally test the mediating role of experimentation proposed.

Finally, more elaborate dependent measures could be developed, drawing on the multi-items reflective and formative measures put forward here.

\section{MANAGEMENT IMPLICATIONS}

The results have several important management implications. First, top managers who would like their companies to adopt and implement a BSC approach would benefit from personal involvement in the matter, and from giving the finance department a role in activating the process. Second, including a trial stage can help increase the value of the BSC for the organization and help its subsequent implementation. Experimentation helps to decrease the ambiguity surrounding the BSC and allows for customization, i.e., helps to identify which indicators of a scorecard work best before rolling out the total concept. Later on in the adoption process, the results from experimentation can be used to convince departments and individuals of the usefulness of the innovation for managing business processes and firm performance.

To increase the effectiveness of the implementation of the BSC, the negative effect of the organization's level of formalization should be reduced. This can be done by involving department heads and empowering them. In the case of the BSC, for instance, heads could be requested to come up with good performance measures for their departments and functional areas. This process will benefit from excellent interdepartmental communications and openness. Showing positive results from in situ experimentation may help to build trust, which can help to persuade people to embrace the innovation. In the case of the BSC this means stressing the tool's usefulness for careful and solid monitoring and managing of business processes, and emphasizing its role for integrating and optimizing processes rather than as an output control instrument.

\section{ACKNOWLEDGEMENTS}

We are grateful to two anonymous reviewers for their helpful comments and suggestions.

\section{References}

Ahn, H. (2001). Applying the balanced scorecard concept: An experience report. Long Range Planning, 34(4), 441-461.

Assiri, A., Zairi, M., \& Eid, R. (2006). How to profit from the balanced scorecard. An implementation roadmap. Industrial Management and Data Systems, 106(7), 937-952.

Baines, A., \& Langfield-Smith, K. (2003). Antecedents of management accounting change: A structural equation approach. Accounting, Organizations and Society, 28(7-8), 675-698. 
Barclay, D., Higgins, C., \& Thompson, R. (1995). The partial least squares (PLS) approach to causal modeling: Personal computer adoption and use as an illustration. Technology Studies, 2, 285-309.

Chin, W. W. (1998). The partial least squares approach for structural equation modelling. In G. A. Marcoulides (Ed.), Modern methods for business research (pp. 295-336). New York: Lawrence Erlbaum Associates.

Covin, J. G., \& Slevin, D. P. (1991). A conceptual model of entrepreneurship as firm behavior. Entrepreneurship Theory and Practice, 16(1), 7-25.

Damanpour, F., \& Schneider, M. (2006). Phases of the adoption of innovation in organization: Effects of environment, organization and top managers. British Journal of Management, 17, 215-236.

Diamantopoulos, A., Riefler, P., \& Roth, K. P. (2008). Advancing formative measurement models. Journal of Business Research, 61, 1203-1218.

De Geuser, F., Mooraj, S., \& Oyon, D. (2009). Does the balanced scorecard add value? Empirical evidence on its effect on performance. European Accounting Review, 18(1), 93-122.

Fornell, C., \& Larcker, D. F. (1981). Evaluating structural equation models with unobservable variables and measurement error. Journal of Marketing Research, 18(1), 39-50.

Frambach, R. T., \& Schillewaert, N. (2002). Organizational innovation adoption. A multilevel framework of determinants and opportunities for future research. Journal of Business Research, 55, 163-176.

Hambrick, D. C., \& Mason, P. A. (1984). Upper echelons: The organization as a reflection of its top management. Academy of Management Review, 9(2), 193-206.

Hoque, Z., \& James, W. (2000). Linking balanced scorecard measures to size and market factors: Impact on organizational performance. Journal of Management Accounting Research, 12(1), $1-15$.

Ittner, C. D. (2008). Does measuring intangibles for management purposes improve performance? A review of the evidence. Accounting and Business Research, 38(3), 261-272.
Ittner, C. D., Larcker, D. F., \& Randall, T. (2003). Performance implications of strategic performance measurement in financial services firms. Accounting, Organizations and Society, 28(7-8), 715-741.

Jaworski, B. J., \& Kohli, A. H. (1993). Market orientation - Antecedents and consequences. Journal of Marketing, 57(3), 53-70.

Jenkins, M., \& Meer, D. (2005). Organic growth, profiting from union of finance and marketing. Financial Executive, 21(8), 39-44.

Kaplan, R. S. (2010, March). Conceptual foundations of the balanced scorecard. Working Paper 10-074, Harvard Business School, Boston.

Kaplan, R. S., \& Norton, D. P. (1992). The balanced scorecard - Measures that drive performance. Harvard Business Review, 70, 71-79.

Kaplan, R. S., \& Norton, D. P. (1996). The balanced scorecard: Translating strategy into action. Boston: Harvard Business School Press.

Kaplan, R. S., \& Norton, D. P. (2001). The strategy focused organization. Boston: Harvard Business School Press.

Kaplan, R. S., \& Norton, D. P. (2004). Strategy maps: Converting intangibles assets into tangible outcomes. Boston: Harvard Business School Press.

Kaplan, R. S., \& Norton, D. P. (2006). Alignment: Using the balanced scorecard to create corporate synergies. Boston: Harvard Business School Press.

Krumwiede, K. R. (1998). The implementations stages of activity-based costing and the impact of contextual and organizational factors. Journal of Management Accounting Research, 10, 239-277.

Lee, C., Chu, P. Y., \& Tseng, H. L. (2009). Exploring the relationship between information technology adoption and business process reengineering. Journal of Management \& Organization, 15, 170-185.

Malmi, T. (2001). Balanced scorecards in Finnish companies: A research note. Management Accounting Research, 12(2), 207-220.

Meyer, A. D., \& Goes, J. B. (1988). Organizational assimilation of innovation: A multilevel contextual analysis. Academy of Management Journal, 31(4), 897-923. 
Meyers-Levy, J., \& Tybout, A. M. (1989). Schema congruity as a basis for product evaluation. Journal of Consumer Research, 16(1), 39-54.

Miles, R. E., \& Snow, C. C. (1978). Organizational strategy, structure and process. New York: McGraw-Hill.

Miller, D., \& Friesen, P. (1982). Innovation in conservative and entrepreneurial firms: Two models of strategic momentum. Strategic Management Journal, 3, 1-25.

Modell, S. (2009). Bundling management control in innovations: A field study of organizational experimenting with total quality management and the balanced scorecard. Accounting, Auditing and Accountability Journal, 22(1), 59-90.

Naman, J., \& Slevin, D. (1993). Entrepreneurship and the concept of fit: A model and empirical tests. Strategic Management Journal, 14, 137-153.

Olshavsky, R. W., \& Spreng, R. A. (1996). An exploratory study of the innovation evaluation process. Journal of Product Innovation Management, 13(6), 512-529.

Pfeffer, J. (1981). The power in organizations. New York: Harper Business.

Pfeffer, J., \& Salancik, G. R. (1977). Organizational context and the characteristics and tenure of hospital administrators. Academy of Management, 20(1), 74-88.
Ringle, C. M., Wende, S, \& Will, A. (2005). SmartPLS 20 (beta). Accessed from http://www. smartpls de

Rogers, E. M. (2003). Diffusion of innovations. New York: The Free Press.

Santa, R., Ferrer, M., Bretherton, P., \& Hyland, P. (2009). The necessary alignment between technology innovation effectiveness and operational effectiveness. Journal of Management and Organization, 15, 155-169.

Speckbacher, G., Bischof, J., \& Pfeiffer, T. (2003). A descriptive analysis on the implementation of balanced scorecards in German-speaking countries. Management Accounting Research, 14(4), 361-387.

Wolfe, R. A. (1994). Organizational innovation: Review, critique and suggested research directions. Journal of Management Studies, 31, 405-431.

Wouters, M. J. F., \& Wilderom, C. P. (2008). Developing performance-measurement systems as enabling formalization: A longitudinal field study of a logistics department. Accounting, Organizations and Society, 33, 488-516.

Zaltman, G., Duncan, R., \& Holbek, J. (1973). Innovations and organizations. New York: Wiley $\&$ Sons.

Received xx Month 200x

Accepted xx Month 200x 


\section{Appendix A \\ Operational measures utilized for the study constructs}

BSC experimentation (new scale)

To what extend did your firm experiment with the BSC before the actual adoption decision was made? (five-point Likert scale, strongly disagree-strongly agree. New scale).

- Before the actual and final adoption decision was made we experimented, in our organization, with the BSC.

- We adjusted the BSC and its four perspectives developing alternative measures.

BSC implementation (formative measure, drawing on Malmi, 2001; Speckbacher et al., 2003).

Please divide 100 points between the four perspectives of the BSC depending on the amount of attention and number of indicators your organization uses to monitor/measure these areas:

- Financial:____points;

- Customer:____points;

_ Internal business processes:______ points;

- Learning and growth:____ points.

Top management involvement (five-point Likert scale, strongly disagree-strongly agree. Adapted from Zaltman et al., 1973).

Top management involvement is characterized by:

- Being very much involved in introducing performance monitoring throughout the company.

- Understanding that monitoring of the company's key processes using indicators and criteria is essential to the company's success.

- Being well informed and supporting every attempt to improve the company's performance measurement systems.

Influence of finance department (five-point Likert scale, strongly disagree-strongly agree. Adapted from Pfeffer, 1981).

The influence of the finance department is characterized by:

- The finance department having a lot of power in the organization compared to, for instance, marketing and production.

- The management accountants having a strong, sometimes even dominant, position in the organization.

Environmental dynamics (five-point Likert scale, strongly disagree-strongly agree. Based on Miller \& Friesen, 1982; Naman \& Slevin, 1993)

- The level of technological change in our industry causes our products to become obsolete rather quickly.

- In our market changes in customer demand are difficult to predict.

- In our market competitors' behaviour is rather unpredictable.

\section{Intangible assets}

The data regarding an organization's intangible assets were collected using desk research, consulting the consolidated balance sheet in the firms' annual reports. Subsequently, the values for intangible assets were divided by firm size measured by the firm's number of employees (in full time equivalents). 


\section{Appendix A: Continued}

Formalization (five-point Likert scale, strongly disagree-strongly agree. Adapted from Covin \& Slevin, 1991; Jaworski \& Kohli, 1993)

The organization of the company you work for is characterized by:

- A strong emphasis on a uniform and dominant management style.

- A strong emphasis on following current procedures.

- Tight formal control of processes using detailed control systems.

- A strong emphasis on allowing every employee to work in accordance with their function descriptions.

Interdepartmental communications (five-point Likert scale, strongly disagree-strongly agree. Adapted from Covin \& Slevin, 1991; Jaworski \& Kohli, 1993)

The company's interdepartmental communications are characterized by:

- Limited access to important financial and management information of departments (R).

- Intensive internal communications between departments.

- Excellent information exchange between departments, including intense information-sharing.

(R): Indicates reversed score item.

\section{APPENDIX B}

Correlations between latent constructs and reliability information

$\begin{array}{lllllllllll}\text { Mean } & \text { SD } & \text { Composite } & 1 & 2 & 3 & 4 & 5 & 6 & 7 & 8\end{array}$ reliability

1. BSC experimentation

$3.84 \quad 1.27$

0.83

$0.72^{+}$

2. BSC implementation

2.42

3.03

N.A. ${ }^{\prime}$

$0.47^{* *} \quad N A$

3. Top management

3.89

0.81

0.92

0.11

0.23

0.85 involvement

4. Influence of finance

3.07

0.98

0.95

0.60 ** 0.31 * -0.21

0.91

department

5. Intangibles assets

3842.038001 .47

NA

0.19

$0.21-0.06$

0.2

$2.45 \quad 0.86$

0.88

$-0.23$

0.29

$0.24-0.02-0.10 \quad 0.62$ dynamics

7. Formalization

3.15

0.78

0.81

$-0.01-0.34^{\star} \quad 0.23$

0.01

$0.13-0.09$

0.53

8. Interdepartmental

3.05

$0.83 \quad 0.63$

0.120 .41 ** 0.07

$0.26 \quad 0.13$

$0.39 * \star-0.210 .53$ communication

${ }^{\star} p<0.1$ (two-tailed); ${ }^{\star \star} p<0.05 ;{ }^{\dagger}$ Average variance extracted on the diagonal; ${ }^{\star}$ NA, not applicable. 


\section{Queries}

ED1 Please confirm whether the inclusion of short running title 'Experimentation and implementation of the balanced scorecard' is fine.

ED2 Please add "Pfeffer \& Salanick 1978" to the Reference list

ED3 Please confirm whether inclusion of the symbol ' $X$ ' is fine.

ED4 Please provide accessed date for Ringle et al. 2005.

ED5 Please provide received and accepted dates. 